\title{
CATEGORIZAÇÃO, COGNIÇÃO E O ESTILO DE VIDA GOY
}

\author{
Nuno de Sá-Teixeira \\ Universidade de Coimbra
}

\begin{abstract}
Resumo
A categorização é fundamental para o nosso pensamento, nossa percepção, ação e posicionamento no mundo. Todas as vezes que percebemos algo como um tipo de coisa, ou como parte de alguma coisa, estamos a categorizar e a recorrer ao uso de processos cognitivos. Nessa perspectiva, as novas categorias homoeróticas na contemporaneidade surgem de que axiomas? O que é gay, o que é g0y (g-zero-y) e o que não é? Bem como, qual é a fronteira desses conceitos com o comportamento masculino heteroflexível? São questões instigantes sob o enfoque da cognição, da categorização; e, com base em verificação ontológica, este artigo enfatiza o papel de validação exercido pela "confirmação" e "desconfirmação" das crenças acerca de categorias mais fluidas de comportamentos sexuais masculinos que podem estar externalizados. Nesse âmbito, registra-se que não se encontra na proposição g-zero-y erros sejam no sentido da redundância, de inconsistência interna, de partição ou de circularidade conceptual.
\end{abstract}

Palavras-chave: Categorização; Ontologia; Papéis Sexuais; Sexualidade Masculina.

\section{CATEGORIZATION, COGNITION AND THE GOY LIFESTYLE}

\begin{abstract}
The categorization is basic for our thinking, our perception, action, and positioning in the world. When we perceive something as a kind of thing, or as part of something, we are categorizing and resorting to the use of cognitive processes. In this perspective, from which axioms arise the new homoerotic categories in the contemporaneity? What is gay, what is g0y (g-zero-y) and what is not? As well as, what is the frontier of these concepts with the heteroflexible male behavior? These are intriguing questions at perspective of the cognition processes, of categorization based on the ontological verification this paper emphasizes the role of validation exercised by the 'confirmation' and 'disconfirmation' of the beliefs, about categories more fluids of male sexual behaviors that may be externalized, registering that it is not in the proposition g-zero$y$ errors are in the conceptual sense of redundancy, internal inconsistency, partition or circularity.
\end{abstract}

Keywords: Categorization; Ontology; Sex Roles; Male Sexuality.

\section{CATEGORIZACIÓN, COGNICIÓN Y EL ESTILO DE VIDA GOY}

\begin{abstract}
Resumen
La categorización es fundamental para nuestro pensamiento, percepción, acción y posicionamiento en el mundo. Cuando percibimos algo como una especie de cosa, o como parte de algo, estamos categorizando y recurriendo al uso de procesos cognitivos. En esta perspectiva del proceso de categorización, ¿̇las nuevas categorías homoeróticas de que axiomas surgen? ¿Qué es gay, qué es g0y ( $\mathrm{g}$-cero-y) y qué no lo es? Así como, ¿cuál es la frontera con el comportamiento masculino heteroflexible? Estas son preguntas intrigantes en la perspectiva del proceso de la cognición, de la categorización y basado en verificación ontológica, este artículo hace hincapié en el papel de la validación ejercida por la 'confirmación' y la 'desconfirmación' de las creencias, sobre categorías más fluidas de los comportamientos sexuales masculinos que pueden estar externalizados. En conclusión, se registra que no se encuentran en la proposición g-cero-y errores en el sentido de redundancia, inconsistencia interna, partición o circularidad conceptual.
\end{abstract}

Palabras clave: Categorización; Ontología; Papeles sexuales; Sexualidad Masculina. 


\section{INTRODUÇÃO}

A categorização é uma atividade cognitiva fundamental. Representa uma função essencial nos processos de memória, linguagem, raciocínio e resolução de problemas. É uma atividade que ocorre sempre que dois ou mais objetos, seres ou acontecimentos diferentes são agrupados devido a certa semelhança ou características comuns entre si. Por meio do estabelecimento de categorias ou de conceitos é que o ser humano organiza e representa o conhecimento da realidade.

De facto, o nosso conhecimento do mundo e a nossa habilidade para formar categorias apresentam-se certamente intimamente relacionados. $\mathrm{Na}$ psicologia social, o termo categoria tradicionalmente tem sido adotado para descrever a totalidade de processamento de informações que os percebedores humanos possuem na mente sobre uma classe particular e diante dessa classe são capazes de inter-relacioná-la em relação a outras classes de coisas presentes do mundo (Macrae \& Bodenhausen, 2000; Park \& Judd, 2005; Moskowitz, 2006).

Conforme disposto na literatura, até mesmo organismos mais simples, como animais e bebês humanos, também têm conceitos e formam categorias (Mareschal, Quinn \& Lea, 2010). Pode-se situar esse ensaio como uma visão inserida nos processos básicos da aquisição do conhecimento; quando a informação é decodificada após a passagem no sistema inicial de filtragem, esta é tratada e analisada como reconhecimento, discriminação, identificação, comparação e classificação. Dentre esses processos, há o processo que é o da classificação chamado actualmente de categorização.

Desde a época de Aristóteles, já há registros de que havia a preocupação com as práticas de nomear, definir e categorizar (Aranalde, 2009). Com o desenvolvimento de estudos na ciência cognitiva, a visão de como categorizamos sofreu modificações no sentido do seu alargamento em que a categorização passou de um processo cognitivo individual para também um processo cultural e social de construção da realidade, que organiza conceitos, parcialmente baseados na ordem do pensamento e na capacidade da intelectualidade.

O rótulo g0y (escrito com um zero) é recente no contexto social e meche de forma direta com o processo cognitivo essencial de categorização. 0 comportamento homoerótico (Almeida, Castro, Razuck \& Mamede, 2017) e/ou o comportamento hétero flexível a ele intrínseco (Castro, 2015; Wikipédia, 2016) conceitualmente repensam o já estabelecido e rearranjam de forma positiva, em especial, as visões arraigadas na cultura ocidental acerca do comportamento sexual masculino.

O objetivo desse ensaio é, então, diante do conhecimento e do aporte teórico acerca do fenômeno cognitivo da categorização procurar avaliar e esclarecer alguns mecanismos psicológicos envolvidos na manifestação do julgamento estereotipado dos estratos do homoerotismo masculino, a enfatizar o 
papel de validação exercido pela confirmação e desconfirmação das crenças por meio de critérios ontológicos.

\section{O PROCESSO DE CATEGORIZAÇÃO}

A informação perceptiva é fundamental na definição das extensões de uma categoria, porque a categorização não é feita artificialmente, mas, sim, a levar em conta as informações do mundo a que pertencemos e como respondemos a elas. Na categorização, o reconhecimento das similaridades e diferenças leva à criação de um conhecimento novo, pelo agrupamento de entidades, de acordo com as similaridades e as diferenças observadas.

As categorias de forma geral possuem interligações também com outras classes, que por sua vez tornam apenas as fronteiras conceptuais mais difusas (ou seja, com fronteiras mal delimitadas). No estudo específico das categorias difusas, é usual construir diversos modelos preditivos que traduzem axiomática as estratégias cognitivas de categorização mais fluidas (Nosofsky, 1988; Wainer \& Madeira, 1994). Tais modelos pressupõem fundamentalmente a construção dessas categorias a permitir, deste modo, a axiomatização realizada aprioristicamente a partir das estratégias cognitivas dos indivíduos.

Muitos autores da literatura da área de ciência cognitiva consideram os termos categorização e conceitos como sinônimos, ou como portadores de uma ambiguidade entre eles a exemplo nós temos: Gardner, 2003; Jacob e Shaw, 1998; Smith e Medin, 1981; e mesmo Russel, 1945, autores que em seu conjunto mostram também que o tema sobre: Como se forma um conceito, não é recente na área da psicologia e de ciências sociais. Entretanto, em que pese a ambiguidade intrínseca entre eles, geralmente o termo conceito é usado para referir-se a uma representação mental de um objeto, ou uma unidade do conhecimento, ou a uma representação "do que é", que pode ocorrer por meio da linguagem ou não.

Já o termo categoria remete à formação da combinação dos significados dos conceitos pelas suas associações, baseada na similaridade entre eles. Muito embora o foco deste trabalho esteja na categorização enquanto processo cognitivo, fica o registro que a formação de conceitos e o processo de categorização, são fenômenos inter-relacionados e inesperáveis, conforme pontuam Johnson-Laird e Wason (1997, p. 170), em tradução livre: "Qualquer cognitivista interessado em processamento das ideias tem que lidar com a questão do que é um conceito" e como ele é adquirido.

Smith e Medin (1981) afirmam que, sem os conceitos, a vida mental poderia ser caótica. Vão mais além, quando afirmam que os conceitos dão ao nosso mundo estabilidade, pois capturam a noção de que os objetos ou eventos são diferentes em alguns aspectos e, por isso, podem ser pensados e respondidos conforme nós já os tenhamos elaborados cognitivamente. Pode-se 
dizer que nessa perspectiva os conceitos nos permitem também ir além das informações já adquiridas, através de percepções de características de objetos ainda não plenamente percebidos, mas inferidos.

Russel (1945), ganhador do prêmio Nobel em 1950, ao realizar uma grande revisão das diversas filosofias (antigas, católicas e modernas) mostra uma perspectiva história sobre diversas formas de o ser humano ver e interpretar o mundo e as coisas que o cercam, e afirma incisivamente que um ser humano sem conceitos e sem pré-conceitos - não existe. Gregory Murphy em uma tradução livre (Murphy, 2004, p. 1) aponta que conceitos são "um tipo de cola fluida mental que amarra nossas experiências passadas com nossas interações presentes com o mundo, porque eles são conectados entre si na grande estrutura do conhecimento".

Sobre a categorização, Jacob e Shaw (1998) dizem que é um processo cognitivo de dividir as experiências do mundo em grupos de entidades, ou classes, para construir uma ordem mental. Markman (1989) descreve a categorização como um mecanismo cognitivo fundamental que simplifica a interação individual com o ambiente: não somente para facilitar o armazenamento e a recuperação da informação, mas, também, para reduzir a demanda da memória humana.

Categorizar é agrupar entidades (eventos, fenômenos, objetos, ideias, ações, etc.) por semelhança e por diferenças. Para Piedade (1983), este é um processo mental habitual do homem, pois vivemos automaticamente a classificar coisas e ideias, a fim de compreender e conhecer. Para Gardner (2003), as categorias têm uma estrutura interna, centrada em protótipos ou estereótipos, e outros exemplares que na estrutura metafísica da cognição são definidos como mais ou menos periféricos, a depender do grau em que eles compartilham com as características cruciais do protótipo mental conceptual e central.

A informação perceptiva é fundamental na definição das extensões de uma categoria, porque a categorização não é feita pelo humano levando-se em conta as informações do mundo a que pertencemos e como respondemos a elas. $\mathrm{Na}$ categorização, o reconhecimento das similaridades e diferenças levam à criação de um conhecimento novo, pelo agrupamento de entidades, de acordo com as similaridades e diferenças observadas (Lima, 2007).

As categorias são identificadas como conceitos elementares, isto é, como princípios que permitem identificar as notas essenciais que caracterizam um objeto de conhecimento. A partir desta operação mental de identificação, é possível formular conceitos empíricos, ou seja, buscar uma equivalência entre como o objeto se apresenta e a representação mental que se faz dele e de suas relações com outros objetos. As categorias são concebidas como metaconceitos que permitem a efetiva conceitualização de objetos passíveis de serem conhecidos, organizados e classificados. Portanto, elas são elementos intermediários entre os conceitos e a realidade cognoscível (Aranalde, 2009). 
As categorias em Aranalde (2009) assumem uma perspectiva de metaconceitos ao se pautar na relação e na experiência existente não apenas individual, mas entre os indivíduos e a realidade; a realidade cognoscível seria, então, o plano para a realização da categorização, apesar de se tratar de um processo mental individual, a categorização é vista como a ligação de um plano ideacional com a realidade experimental que se conhece de forma constrastiva.

É isso, o acto constratisvo, como sugere Marcuschi (2006) que permite a compreensão de uma referenciação estável entre os conceitos e, outras que se associam à relação discursiva e intersubjetiva do cognitivo com o mundo. Nesse âmbito Aranalde (2009) complementa e afirma que são as categorias que permitem que se afirme 'o que é e o que não é'.

Barité (1998) ao dissertar sobre o nível de abstração presente nas categorias, aponta que estas não são componentes dos objetos do mundo como alguns filósofos afirmaram, estão fora do mundo real. São formas eleitas, externas e autônomas - até mesmo arbitrárias. Para Barité, definimos as categorias como concepções abstratas (cuja essência pode ser analisada a partir de uma perspectiva ontológica ou semântica), e são essas concepções mentais, que por sua natureza, são as formas mais simplificadas que podemos ter para analisar qualquer fenômeno e situá-lo em determinada posição em relação a um objeto ou referência.

Howard Gardner (2003, p. 360), ao abordar a categorização, resgata a definição dada pelos gregos aos seres humanos como "bípedes sem penas". 0 autor afirma que, com esta frase hoje soa esquisita, mas os gregos não queriam apenas traçar uma definição sucinta da espécie, mas exemplificar que os objetos do mundo podem ser categorizados em grupos e que estes são definidos por certos critérios, que podem simplesmente ser atingidos pelo intelecto.

\section{A COGNIÇÃO E A ONTOLOGIA - OU ESSÊNCIA DAS COISAS}

Diante do processo de categorização, que em seu âmago é essencialmente um processo cognitivo - que se compartilhado pode vir a ser também um processo sociocognitivo - é completamente lícito afirmar, portanto, que se encontra organizado na memória humana conhecimentos a respeito dos grupos $\mathrm{x}, \mathrm{y}, \mathrm{z} \ldots n$ que dizem respeito as mais diversas categorias sociais com as quais a interação é frequente.

Para Greenwald e Banaji (1995) esse repertório de conhecimento gera expectativas e, tais expectativas fornecem um certo critério ou, pelo menos, um pré-conceito (isto é, um conceito deficiente ou mal formulado) e as expectativas funcionam como uma espécie de guia, que permite determinar se os comportamentos eliciados pelo grupo $\mathrm{x}, \mathrm{y}, \mathrm{z} \ldots n$, se enquadram ou não dentro daquilo que se imagina como o comportamento esperado para os membros daquela categoria. 
O contexto cognitivo na categorização pode ser visualizado em consonância com Van Dijk (2004) como algo dinâmico que muda de acordo com as diversas interações linguística entre os indivíduos, princípios causais, convenções e demais restrições sobre as sequencias dos eventos e ações. É, assim, algo variável e flexível, de base intrinsecamente sociocognitiva, que concede a categorização uma elasticidade e dinamicidade, sobretudo, relacionada a sua condição social, cuja interação faz-se rever conceitos, com refazimento de atribuição causal e uma busca mais refinada das essências das classes/categorias.

Pela perspectiva de Van Dijk (2004) de cunho cognitiva e interacionista, no fenômeno de rever conceitos e também categorias, há que se considerar princípios que orientam a noção de contexto. Dentre esses, cabe citar a abstração teórica e cognitiva derivada da situação físico-biológica e maturidade dos indivíduos e a presença de recursos para o processamento rápido da informação nos diferentes contextos, ou seja, existem estruturas que sugestionam a repulsa ou o reconhecimento de um conceito sob determinado olhar.

Aprender sobre o fenômeno das categorias é um processo complexo e estes diversos elementos sintetizados na Figura 1, podem relacionar-se tanto com processos metafísicos e cognitivos, como já aqui relatado, como também podem relacionar-se com diferentes ocorrências físicas no cérebro e, nesse sentido, segundo Maddox e Ashby (2004), parece provável que esses diferentes aspectos dos conceitos sejam realizados por diferentes estruturas neurais.

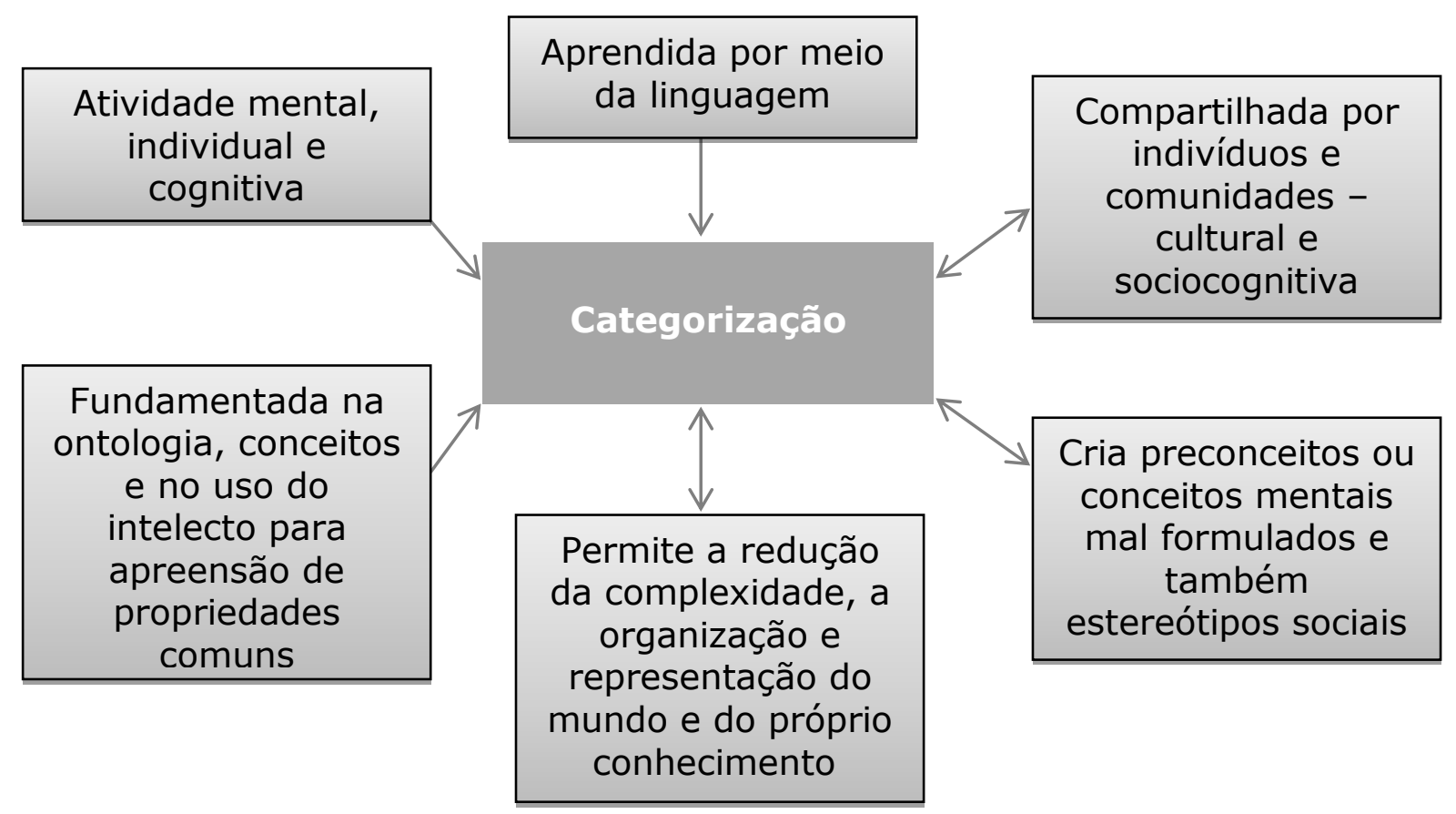

Figura 1. Síntese gráfica dos elementos proeminentes no fenômeno da categorização. 
Se tudo isso é aceitável, pode-se dizer que o pensamento categórico exerce uma influência muito grande sobre a percepção social. Essa influência se manifesta por duas vias distintas. Por um lado, é possível afirmar que o processamento da informação, característico de toda a percepção social, é guiado pela estrutura de conhecimento a respeito da categoria. Por outro lado, pode-se supor que uma vez ativada, a estrutura do conhecimento permite a elaboração de uma série de inferências, especialmente aquelas que envolvem o julgamento, a formação de impressões ou mesmo a realização de avaliações sobre a categoria formada.

Assim, por meio das inferências e generalizações, nascem tanto os estereótipos sociais quanto os preconceitos - nesse caso, tanto os pré-conceitos no sentido de conceitos prévios e precariamente formulados do ponto de vista cognitivo, quanto preconceitos no uso de lugar comum da discriminação social. Conforme literatura, muitas destas inferências podem até ser apropriadas, embora em uma parcela significativa das vezes elas se assentam puramente em julgamentos estereotipados (Fiske, 2000; Pereira, 2002).

O papel fundamental da categorização na sobrevivência do organismo quanto da própria sociedade parece ser indubitável. A possibilidade que ele oferece de permitir que o agente cognitivo humano possa tratar o novo e inesperado em termos de crenças mais gerais e antigas, quanto até mesmo emprenhar-se na busca da essência das categorias formadas, ou do ser, que é função da ontologia, ou até mesmo a economia cognitiva no caminho dos prejulgamentos são essenciais para a sobrevivência do indivíduo e da espécie.

Como o cognitivo dispõe de um conjunto abrangente de crenças relativamente estáveis a respeito de diversas categorias sociais, pode-se verificar que nos diversos ambientes sociais circulam crenças sobre as diversas categorias e que essas crenças, também, envolvem a sexualidade e sua expressão. Nessa direção, os ambientes sociais são espaços privilegiados para a manifestação frequente de julgamentos fundamentados nas categorias cognitivas, mas que podem envolver: tanto pré-conceitos pura e simplesmente, quanto à busca da essência do que representa cada categoria.

Em busca da essência existe o campo de estudo - ontologia; o termo ontologia vem do grego: onto (ser) e logos (palavra) e, de acordo com Moreira, Alvarenga e Oliveira (2004), foi cunhado por Rudolf Goclenius em sua obra Lexicon philosophicum e por Jacob Lorhard em Theatrum philosophicum, no século XVII. Na busca do ser das palavras, sob o ponto de vista da Filosofia, a ontologia é um arcabouço sobre a natureza da existência.

A ontologia substancial de Aristóteles apesar de várias vertentes atuais constitui a base de toda ontologia que se segue na história. Ela considera que as substâncias individuais têm ascendência sobre as propriedades (qualidades das coisas, que permitem categorizações), pois as propriedades possuem existência independente $e$, as substâncias, podem incluisve ser chamadas negativamente 
de não-substâncias pois seriam de natureza não necessariamente físicas (Castro, 2008).

O pensamento moderno é fortemente marcado pela tríade racionalista de René Descartes, Bento Espinoza e Gottfried von Leibniz. Descartes introduziu o dualismo da substância (substância espiritual e substância material), Espinoza apregoou o nonismo da essência (só Deus é essência) e Leibniz apresentou a definição da essência como concptus completus (conceito com completude). Conforme apresenta Castro (2008), tais pensadores influenciaram de maneira marcante a transformação do pensamento da ontologia, e por conseguinte, 0 olhar racional sobre as classes, os conceitos e as essências das coisas.

Soergel (1999) diz que ontologia é um estudo da classificação de categorias básicas. O autor faz ainda uma defesa no sentido que o termo "ontologia" é apenas um novo nome para "classificação". Assim, o autor sugere que os estudos sobre ontologias possam não apenas basear-se em posicionamentos filosóficos, mas também basear-se em técnicas racionais já consolidadas no contexto da Ciência da Informação. Nessa mesma linha, Furgeri (2006) define ontologia como uma técnica que permite organizar a informação e auxiliar sua recuperação, através de um vocabulário de termos categorizados que descrevem determinada realidade ou essência. Ambos os autores enxergam a ontologia através do estabelecimento de vocabulários comuns e interpretações semânticas dos termos.

No cenário das interpretações semânticas que surgem com a introdução de um novo termo, no caso dos g0ys escrito com zero, que por sua vez cria uma nova identidade (ou categoria), é possível avaliar a sua ontologia? Ontologias podem ser avaliadas sem incorrer no erro do puro preconceito?

Gómez-Pérez (2001), um dos pioneiros no estudo de avaliação de ontologia, apresenta cinco critérios pelos quais uma ontologia pode ser avaliada. São eles: (1) coerência, que refere-se a saber se é possível obter conclusões contraditórias a partir de definições explícitas; (2) completude, que visa identificar se a ontologia não possui definições incompletas; (3) concisão, quando não há definições desnecessárias e inúteis e outro conceito já seja capaz de definir o grupo (4) capacidade de expansão, refere-se ao esforço exigido em adicionar novas definições ou mais conhecimento para as suas definições, sem alterar o conjunto de propriedades que já estão definidos; e (5) sensibilidade, que se refere a como pequenas mudanças na definição podem alterar o conjunto de propriedades que já estão bem definidas.

Gómez-Pérez (2001, p. 393) deixa claro o objetivo da avaliação de ontologias e, em uma tradução livre, afirma:

A avaliação de ontologias refere-se à construção correta do conteúdo da ontologia, isto é, garantir que a sua definição corresponda corretamente aos requisitos da ontologia e às questões de competência ou reflete corretamente ao mundo real. O objetivo é comprovar a conformidade do modelo de mundo com o mundo 
modelado formalmente. Avaliação de ontologia inclui: cada definição e axioma individual; coleção de definições e axiomas que são declarados explicitamente na ontologia; definições que são importadas de outras ontologias; definições que podem ser inferidas ao utilizar outras definições e axiomas.

As propostas de avaliação de ontologias categóricas que utilizam a abordagem de Gómez-Pérez (2001) também podem servir para a avaliação da validade de uma categoria ou conceito criado. Ou seja, uma maneira na qual uma pessoa avalia a invalidade da ontologia proposta com base nos critérios préestabelecidos, com base especialmente nos três primeiros parâmetros nos referenciados no paragrafo anterior. Esses critérios seriam: Erros de inconsistência, de incompletude e erros de redundância.

Os Erros de inconsistência podem ser verificados em três momentos: por meio dos erros de circularidade, erros de partição e inconsistência semântica. Os erros de circularidade ocorrem quando uma classe é definida como uma especialização, mas é uma generalização de si mesmo (p. ex., uma definição circular que não fornece qualquer informação nova ou útil). Os erros de partição podem definir classificações conceptuais de uma maneira completa e disjunta, uma vez que as partições de subclasse exaustivas apenas adicionam uma restrição de completude aos subconjuntos estabelecidos (p. ex., segmentar sem necessidade ou dividir o não divísivel). E por fim, os erros de inconsistência semântica geralmente ocorrem porque o desenvolvedor faz uma classificação semântica incorreta ( $p$. ex., classificar um conceito como pertencente a uma classe a qual ele realmente não pertence) (Gómez-Pérez, 2001).

Os erros de incompletude ocorrem quando um novo conceito é montado sem contabilizar todos os conceitos já existentes, ou seja, os conceitos existentes em um domínio são ignorados. Erros de redundância são aqueles em que se muda o rótulo e passam a existir duas supostas "categorias", mas ambas refletem exatamente o mesmo conceito, ou seja, isso ocorre quando há duas ou mais classes na ontologia com a mesma definição conceptual, e a única diferença entre as subclasses é apenas o nome ou rótulo (Gómez-Pérez, 2001).

\section{A HETEROFLEXIBILIDADE E O COMPORTAMENTO HOMOERÓTICO ENQUANTO CATEGORIA}

A transgressão ou a rebeldia hetero flexível configura dentro da matriz cultural, hoje ainda hegemônica, uma categoria intermediária tomada como uma possibilidade aberta, sugestiva e a evocar uma criatividade subversiva, que tende a resgatar um comportamento masculino que conforme registros históricos e arqueológicos era típico dos discípulos de Platão na Grécia Antiga. E, por inferência, talvez fosse um comportamento afectivo também encontrado corriqueiramente em outros povos da Antiguidade. Isso possui substratos de coerência em sua ontologia? É uma pergunta que instiga e nos leva a pensar. 
Fratman (2015) mergulha em escritos judaicos - plenamente preservados nas escrituras consideradas sagradas pela chamada nação de Israel; e mostra que considerar o comportamento homoafectivo como "nascido na Grécia Antiga" pode ser um mito. Segundo o autor, nas Leis de Moisés, ou seja, as leis que ditavam o comportamento do povo Hebreu - anterior à civilização Grega; é possível notar que a prática homossexual masculina era plenamente condenada pela Lei no 350 na Ló Tassê (norma proibitiva), mas era totalmente permitido fazer "outras coisas" de caráter homoerótico, desde que não fosse com o seu pai, nem com os seus tios (Ló Tassê 351 e 352, em combinado com a 350).

Nessa mesma direção histórica, a investigar o principal website de difusão dos conceitos homoeróticos-heteroflexíveis, em idioma português (Heterogoy, 2014), nota-se que os profusores na internet destas novas formas de ver o mundo sexual masculino e suas nuances de comportamento mergulham com certa profundidade em achados arqueológicos, registros históricos e mostram com uma série de argumentos plausíveis, uma visão contra factual. Por exemplo, na seção do website denominada "tópicos avançados", os ditos profusores adentram na questão da homoafectividade no Antigo Egito, e contra argumentam, que o que hoje é considerado o registro do primeiro casal gay da história, na verdade a relação existente entre Niankhkhnum e Khnumhotep (Reeder, 2000), não era gay era g0y.

O tema g0y foi exposto na mídia, havendo diversas inserções na imprensa em língua portuguesa, inserções jornalísticas estas as quais em decorrência da limitação de espaço, não me arriscarei citar porque beiram às centenas, mas há que se citar pelo menos uma inserção de mídia, com grande repercussão, por ter ocorrido em talk show de canal de TV aberta (Cecarello \& Castro, 2015), e pela qual esse autor teve contacto à discussão (gay-g0y) pela primeira vez.

Mas o que é uma relação g0y? Pelas diversas inserções na mídia (Cecarello \& Castro, 2015), pelos diversos materiais dispostos em rede sociais, blogs (Ptgay, 2016), pelo exposto no principal website brasileiro (Heterogoy, 2014) e, também, pela exposição na literatura acadêmica (Almeida et al., 2017): um estar g0y nada mais é que um homem que em contacto íntimo com outro homem, não pratica a cópula. Sendo, portanto, uma configuração de relação homo mais afectiva e erotizada.

Nas ideias do filósofo Platão o Eros é a própria expressão do amor. No entanto Platão separava o Eros do amor carnal (i.e. sexual) do Eros do amor que enobrece (i.e. um amor erótico, se transliterado para os termos contemporâneos). Segundo Prieto (2006) em seu levantamento histórico, observa-se que o Eros no contexto intermasculino da Grécia Antiga implicava em duas situações distintas: a da pederastia (em que um homem mais velho podia realizar sexo com um homem mais jovem) e a situação da relação sem conteúdo piguista (isto é, sem relação de activo ou passivo).

A pederastia era presente na Grécia Antiga, mas segundo historiadores era

140 Estudos Interdisciplinares em Psicologia, Londrina, v. 10, n. 1, p. 131-152, abr. 2019 
condenada. Os valores sociais da época a consideravam uma prática altamente pejorativa, um abuso do mais homem mais velho em relação ao efebo inexperiente, mas havia irrestrita permissão aos jogos eróticos, que no caso das interações homoeróticas platônicas, podiam incluir desde a masturbação até o coito interfemural, mas nunca a cópula (Prieto, 2006; Lacerda Neto, 2007).

Platão, Livro VIII (citado em Prieto, 2006, p. 229) coloca que:

(...) esse Eros que é dilacerado em sentidos contrários pelos dois elementos, um que ordena colher a flor de uma juventude e outro que a tornou interdita. O primeiro, com efeito, é amoroso do corpo [e carnal] impele-o a saciar-se, sem nenhum respeito da alma e dos costumes do amado. Só tem desdém o outro pelo desejo do corpo, ele que vê mais do que cobiça e é verdadeiramente a alma que deseja uma outra alma e que pensará que o insulta ao amado ao saciar nesse corpo um apetite carnal. $O$ [correcto] que ele [o efebo] desejaria, cheio de religioso respeito pela temperança, pela coragem, pela magnanimidade, pela sabedoria, era viver eternamente casto com também seu casto amigo.

Convém lembrar que nessa ótica da castidade do platonismo, a ideia de casto não possui o significado de abstinência do homoerotismo. Apenas casto no que diz respeito às relações carnais (i.e, a penetração - segundo Platão), a ser o erotismo visto então como uma gradação especial da sexualidade, como "não se chegar a vias de facto" ou não atingir-se a um ato sexual concreto (Prieto, 2006; Lacerda Neto, 2007).

Se formos justos, o verdadeiro precursor do conceito actual g0y (pelo menos de uma forma mais estruturada) foi o Filósofo Platão. Não à toa o comportamento não piguista foi evocado muito anos depois em 1869 por KarlMaria Kertbeny, o criador da palavra homossexual.

Ao cunhar o termo homossexual, Kertbeny (1869, citado em Takacs, 2004) dividiu a expressão da homossexualidade também em dois tipos: o homoplatônico e o homopiguista. O platonismo (na obra de Karl-Maria Kertbeny eram também chamados de os homens de erotismo platônico, nomossexuais e/ou, ainda, masturbadores) e o piguismo (na obra de Karl-Maria Kertbeny, uma denominação de prática homossexual e exclusiva para os que praticavam o intercurso anal).

Ao destacar a categoria homoplatônica no contexto da homossexualidade, Karl Kertbeny homenageou o comportamento homoerótico que já era comum nos escritros da Grécia Antiga. Registros esses nos quais, o filósofo Platão aplaudia e até mesmo incentivava o erotismo intermasculino e, por sua vez, rechaçava ao comportamento de cópula enquanto umas das práticas da homossexualidade masculina. Kertbeny (1869, citado em Takacs, 2004) ao criar o termo homossexual separava os desejos (homossexualidade como orientação) de comportamentos expressos ou prática (platonismo versus piguismo).

Mas, se o criador da palavra homossexual pensava a homossexualidade segmentada dessa forma, o que aconteceu ao longo da história, para somente o 
conceito piguista estar tão em voga nos dias de hoje? Apenas foi força da cultura? Do uso popular que tendeu ao extremo? Com um olhar na literatura da sexualidade não há como se esquecer da grande repercussão das obras de Alfred Kinsey, hoje considerado o pai da sexologia e, em especial, o teor do livro de Kinsey, Pomeroy e Martin (1948), que ao criar as sete categorias ou as sete possibilidades escalares de expressão da sexualidade masculina, simplesmente "esqueceu" de citar o erotismo homoplatônico como uma possibilidade concreta.

O Relatório de Kinsey (Kinsey et al., 1948) trabalhou estritamente com o observado, como cientista de olhar empiricista, seguiu rigorosamente aos dados de observação e não realizou inferências. Plenamente aceitável. Todavia, uma amostra pode trazer viesses e levar a pesquisa a determinadas conclusões que somente valham para o contexto da amostra e não para a população como um todo; a caber ressaltar que Alfred Kinsey trabalhou a observar as expressões sexuais tendo como amostra os presidiários e ex-presidiários norte americanos.

Então, como uma hipótese possível de que em Kinsey possa ter havido a constatação apenas do acto homossexual e omissão do acto homoerótico (nos modelos platônicos), surge a possibilidade de que, em função da amostra, não se tenha conseguido desenhar as expressões da sexualidade como um todo. De qualquer forma, controvérsias à parte, ao não observar demonstrações de afecto ou de erotismo no sentido de Kertbeny e de Platão (Takacs, 2004; Prieto, 2006), no cenário após a década de 1950 , devido a imensa repercussão de Kinsey et al. (1948), entrou para a história contemporânea a nomenclatura escalar conhecida e que vai em gradações do comportamento totalmente heterossexual (i.e, heteropurista), para o bissexual em diversos níveis, até o comportamento totalmente homossexual (desconsiderando as gradações do homoerotismo).

O conceito homoerótico - a passear conceitualmente também nos atributos do Eros platônico, surge na literatura da Psicologia recentemente (Almeida et al., 2017) e, claro, surpreende, pois traz em seu conteúdo produções ontológicas e conceptuais que se desviam do conceito original hetero compulsório e hegemônico - que exclui da sua pauta a homo afectividade e qualquer contacto íntimo entre homens e, assim, abre uma pauta imersa na bidesejabilidade, que autores como Sigmund Freud assumem como inata. Acontece que ao mesmo tempo nesse jogo conceptual ocorre um movimento de contracultura a buscar e a evocar uma identidade que seja própria; a destacar que dentro do conceito homoafectivo nem todo g0y é necessariamente heterossexual flexível.

As relações e inter-relações entre os conceitos homossexual e homoafectivo (Figura 2), com a nuance também do comportamento homoerótico, é exposta em Castro (2016). O autor no mesmo artigo traz também uma exaustiva pesquisa baseada em forte lastro empírico, a desenhar um perfil goy (no caso heterogoy) que se distancia do perfil gay (no caso totalmente homossexual e não bissexual). O que corrobora a máxima exposta 
em Foucault (1994) que não se recaia no erro de considerar a homossexualidade como uma constante ou unicidade do ponto de vista antropológico.

Castro (2016) levanta pela primeira vez na literatura da sexualidade e na das axiologias, que as preferências sexuais masculinas adultas podem estar também relacionadas com os valores pessoais. A pesquisa baseada em um forte lastro empírico desenha um mapeamento dos diferentes valores pessoais e prioridades axiológicas que estão relacionados com o comportamento g0y e os valores e prioridades axiológicas que motivam o comportamento gay.

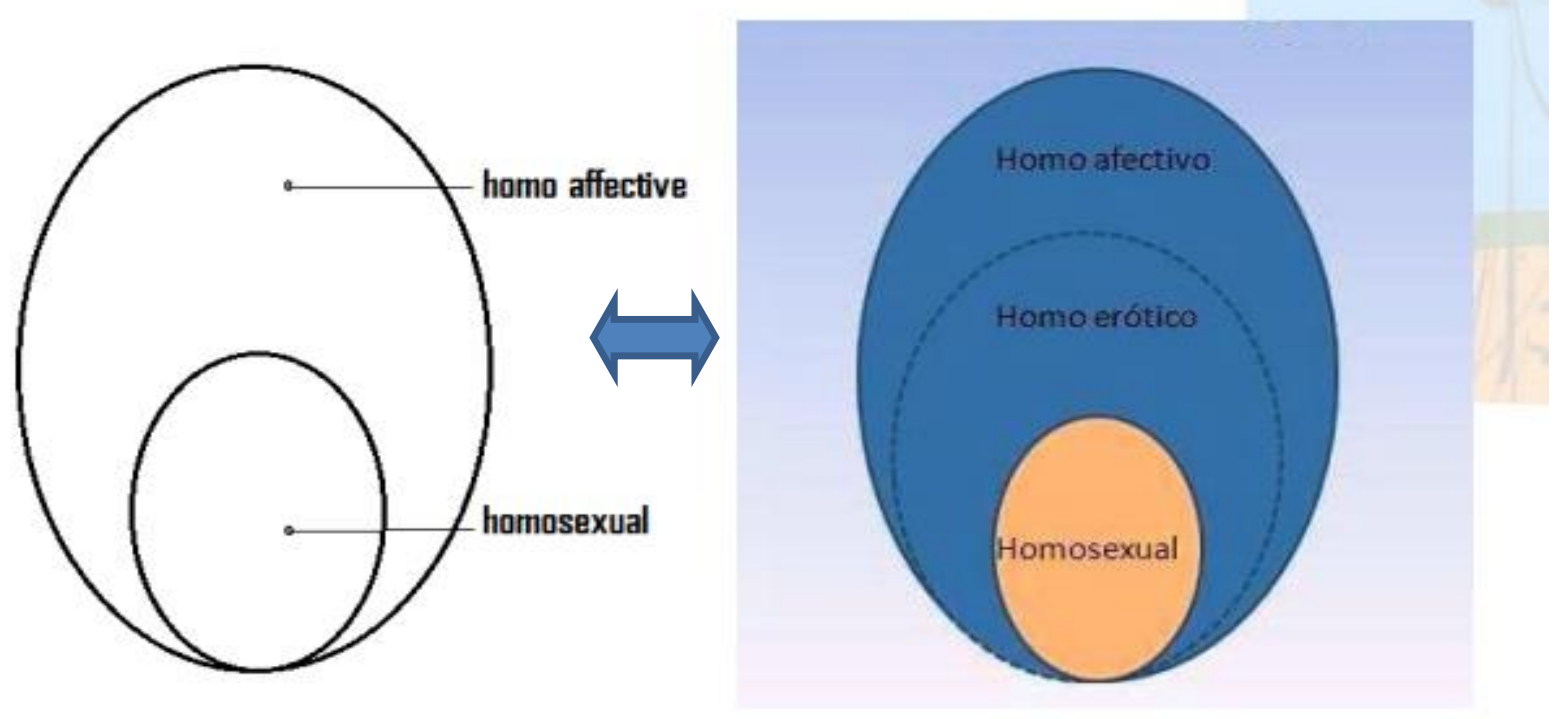

Figura 2 - Inter-relações de conceitos, a demonstrar que o comportamento homoerótico é uma categoria fluida situando-se entre a expressão homoafectiva e a homossexual.

Fonte: Castro (2016).

Os dados abordados em Castro (2016) mostram as prioridades axiológicas dos dois grupos desenhadas com os valores da comunidade gay prezando mais pelo poder e pelo hedonismo e prezando menos pelos valores de tradição. Os heterogoys por sua vez, possuem um perfil a prezar mais pela segurança e pela conformidade. No quadro do ranking dos valores pessoais, os gays valorizam a privacidade, o direito de ter um espaço pessoal e o esplendor das artes e os heterogoys, por sua vez, valorizam a liberdade e o direito de ter uma vida de experiências mais estimulantes, aliado ao valor de estar em paz consigo mesmo.

O trabalho empírico de Castro (2016) foi apresentado no XII CONAGES (Colóquio Nacional Representações de Gênero e de Sexualidades), nesse grande evento brasileiro que discutiu sexualidades e gênero de forma geral, observa-se que dos 473 artigos apresentados, 19 versam sobre a identidade gay e apenas 02 sobre a identidade g0y. O que apenas demonstra que a sensibilidade acadêmica para o tema homoerótico only (i.e. não gay, não piguista) é de facto recente e, no momento, poucos estudos são encontrados. 
O trabalho de Almeida et al. (2017) se destaca nesse sentido e, enquanto um artigo de cunho teórico/conceptual, auxiliou sobremaneira com os objetivos do actual trabalho, que é o de forma ensaística investigar os pressupostos, a ontologia e a própria coerência interna do conceito em seu todo. A buscar aqui como um norte abarcar esse tema polêmico com axiomas da literatura científica e ao máximo - no limite do possível; sem viesses políticos ou até mesmo culturais, pelo uso de termos "consagrados" pela utilização de lugar comum.

Nos argumentos trazidos por Castro (2015) emerge o axioma que o mais importante é o conceito e não o rótulo - ou seja, o relevante não é a palavra utilizada ou o código compartilhado socialmente para relacionar-se ao conceito. No caso o rótulo g0y e o seu conceito estendido para o heterogoy (ou seja, heterossexual flexível), ocorre em fenômeno contrastivo com outro rótulo de uso mais comum: o rótulo gay. O que o faz recair justamente no conflito inicial como bem aborda Norenzayan et al. (2002), que configura o jogo ou duelo cognitivo entre um conceito mais elaborado, que recorre à etimologia da palavra homossexual (aparentemente mais justo pois vai em prol da diversidade) versus uma visão que é cultural e, por isso mesmo, mais difundido e introjectado na mente das pessoas, ou pelo menos, em boa parte da população ocidental.

A Figura 3 traz a noção de que uma vez resgatado da história um conceito que estava obsoleto do ponto de vista social, cuja ontologia é de natureza intermediária e de natureza interacionista, esbarra-se então em vários outros conceitos cuja inter-relação é complexa. Complexa porque conceitualmente o conjunto ilustrado na Figura 2, não se esgota em si mesmo e o conjunto homoafectivo interage constantemente com a heterossexualidade:

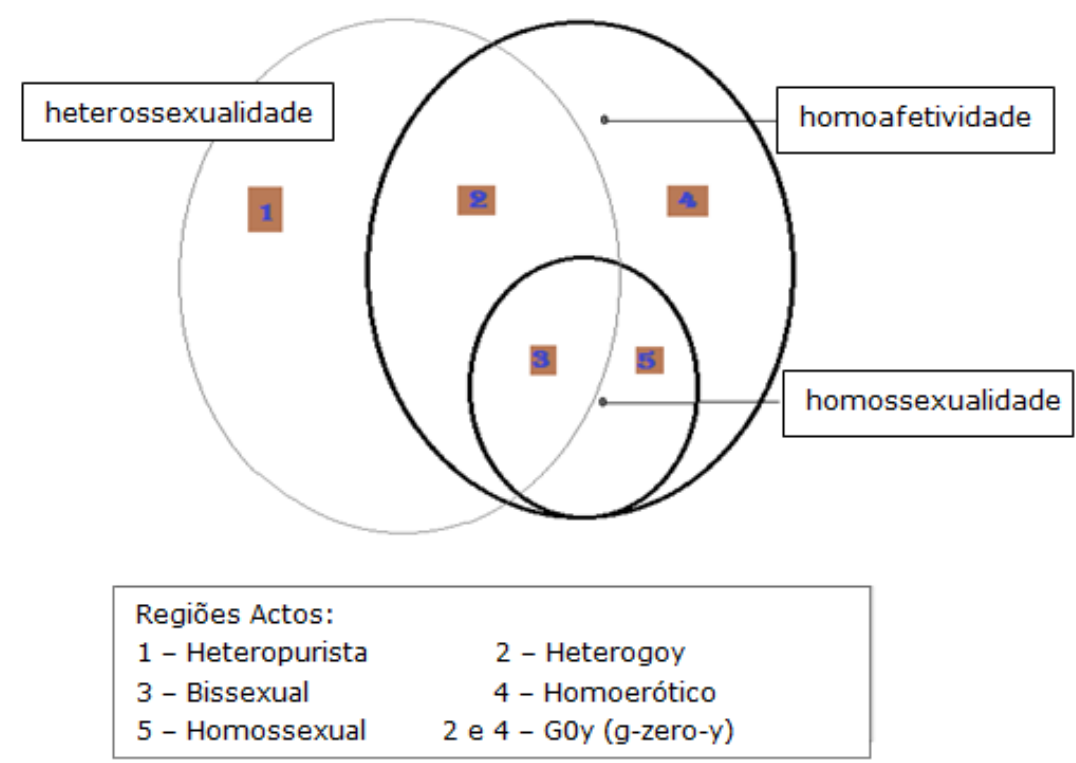

Figura 3 - Diagrama acerca da interação entre a heterossexualidade e as instâncias homo afectivas, ilustrando a região híbrida de apropriação do g0ys.

144 Estudos Interdisciplinares em Psicologia, Londrina, v. 10, n. 1, p. 131-152, abr. 2019 
Fonte: Adaptado e traduzido de Almeida et al. (2017).

Do lado oposto, embora não seja encontrado nenhum texto de caráter mais acadêmico ou científico em sentido de oposição, alguns militantes LGBTs (Movimento social de Lésbicas, Gays, Bissexuais e Transgêneros) como Mott (2014) lançam a máxima que gay e g0y são exatamente a mesma coisa - ou, nas palavras típicas do contexto desse trabalho, os dois seriam a mesma categoria ou representariam o mesmo conceito. Mas, nem todo militante LGBT pensa assim, o website Portugal Gay (Ptgay, 2016), em exemplo, considera o movimento g0y de facto diferenciado e o enxerga de modo positivo.

No entanto, se o rótulo gay usa como base o termo homossexual e se o termo cunhado pelo seu fundador possui uma conotação específica comportamento piguista; e hoje após a década de 1970, encontra-se expandido na cultura e pela força do uso, está generalizado para qualquer comportamento homo - seja ele afectivo, sexual ou erótico; a palavra gay, importada dos Estados Unidos utilizada dessa forma genérica, trata-se de um rótulo vinculado a um conceito ou trata-se de um pré-conceito e de uma pseudoontologia sem base epistemológica?

Aprender sobre essas categorias é um processo complexo que envolve ver exemplares (por exemplo goys na vida real), ouvir ou ler descrições gerais (o que é heteroflexibilidade e o que não é heteroflexibilidade), conhecimento acadêmico (Almeida et al., 2007; Castro, 2016), conhecimento geral (população, conteúdo exposto na mídia) e aprender a regra ocasional ou estrutural (diposta nos difusores do comportamento homoerórico).

Uma vez apreendida as categorias homoafectivo, homoerótico e heteroflexibilidade, todas essas categorias envolvidas com o actual macro-rótulo g0y - cuja ontologia procurou-se mergulhar, investigar e sobretudo avaliar no que diz a sua estrutura interna; nessa direção, do ponto de vista dos processos psicológicos cognitivos, processo de categorização e o lado mais operacional de avaliação das Ciências da Informação disposto e Goméz-Pérez (2001), é possível realizar uma síntese no que diz respeito à coerência, completude, concisão - que indicaria erros de precisão de conceito; e também a capacidade de expansão e sensibilidade desse mesmo conceito (Tabela 1 ). 
Tabela 1.

Visão global da avalição da taxinomia g0y, conforme avaliação da sua ontologia Síntese da avaliação

Critério De validação De invalidação

- Erro de circularidade: Não verificado. A taxonomia apenas torna o homossexual pleno um subconjunto da categoria homoafectiva, que é maior.

- Erro de partição: Uma vez que o termo traz em seu bojo uma partição de subclasse a atual ideia de gay que é cultural vigente, levaria a crer em primeira instância que o novo termo apenas adiciona uma restrição

O conceito g0y possui coerência ontológica ao buscar os conceitos originais (Antigo Egito, Leis de Moisés no povo hebreu, Platão na Grécia Antiga, Kertbeny criador A da palavra homossexual, etc.) e assim, dessa forma resgatar que desde 0 início, a homossexualidade masculina não era uma categoria única, mas era sim segmentada.

de completude ao conjunto homossexual estabelecido e assim o segmentaria sem necessidade. Mas na Figura 2, torna-se mais claro que não é uma restrição, mas sim uma ampliação.

Erro de inconsistência semântica: Em um primeiro olhar e mais superficial, leva-se a crer que o g0y que apresenta uma tendência à bidesejabilidade erótica tende a forçar a classificação do seu comportamento como sendo típico do heterossexual. Mas envolver o atributo da homoafectividade tipicamente não pertencente ao conceito mais normativo/ortodoxo ao qual ele realmente não pertence, a ontologia da heteroflexibilidade (g0y) não recai nesse erro, pois o heterogoy é uma outra categoria de hetero, sobretudo marcado por um comportamento - hoje claramente ainda culturalmente não típico; sendo um conceito behaviorista que mesmo mais flexível não invade a categoria de bissexual pleno em sua semântica.

Não é possível avaliar nesse momento, pois o conceito homoplatônico ficou em estado de latência e ressurgiu na literatura da psicologia, B agora com Almeida et. al. Recente demais, para avaliar se é completo ou não. Aparentemente tenderá a amadurecer e ampliar a sua completude.
Os erros de incompletude ocorrem geralmente um novo conceito é montado sem contabilizar todos os conceitos já existentes, eles, ou seja, os conceitos existentes em um domínio são ignorados. Nesse sentido, talvez conceitos apregoados pelo movimento LGBT (Lésbicas, Gays, Bissexuais e Transgêneros) estejam sendo ignorados. Nesse caso seria um erro duplo dos dois lados, pois LGBTs também ignoram diversas ontologias acerca da homossexualidade e tendem a encará-lo como facto de saída única, para intentar 
mais força política. Talvez ambos precisem amadurecer de uma forma dialética.

O conceito g0y é conciso
e não recai em o conceito bissexual não seria capaz de
tautologia, a categoria abarcar tudo? Se assim fosse, o erro de
aparentemente nasce e redundância estaria posto, pois ocorreriam
cresce pela aflição de duas classes na ontologia com a mesma
homens que não se definição, ou seja, a única diferença entre
sentem pertencentes a as 'subclasses' seria o nome (i.e. ao invés
nenhuma das categorias de chamar de bisex, chamar de heterogoy,
sexuais (Straight, gay, apenas por uma preferência de rótulo),
bisex) e nesse sentido mas para além disso, na Figura 3 nota-se
não há definições que o bissexual masculino possui o seu
desnecessárias e inúteis, locus. Não sendo conceitos redundantes.
elas servem para marcar
uma (nova) identidade.
O conceito tenderá a se expandir e tornar cada vez mais difuso e fluido
o que antes era apenas dicotômico.
Em pouco tempo houve mudanças, se antes o g0y era apenas o
'rebelde' heterossexual moderno /flexível, pequenas mudanças na
definição já alteraram o conjunto de atributos e hoje conceitualmente
já incorporam também os homoeróticos exclusivos.

Nota. A. Coerência; B. Completude; C. Concisão; D. Capacidade de Expansão; E. Capacidade de sensibilidade.

\section{CONSIDERAÇÕES FINAIS}

Com o objetivo de avaliação ontológica, diante do aporte teórico acerca do fenômeno cognitivo da categorização e a enfatizar o papel de validação exercido pela confirmação e desconfirmação das crenças, nota-se sobremaneira, que no que diz a estrutura interna não se observa atributos de invalidação do conceito homoerótico g0y.

Uma vez escalonados os comportamentos homoafectivo, homoerótico e as instâncias de interação com a heteroflexibilidade masculina, também envolvida, torna-se possível estudar e realizar uma síntese no que diz respeito à coerência, completude, concisão - que indicaria erros de precisão de conceito; e também a propriedade de expansão e sensibilidade concpetual g0y, a indicar conforme esse estudo tratar-se de uma categoria ampla e de fronteiras difusas.

Hoje é mais comum trabalharmos com categorias difusas porque os limites entre uma categoria e outra são muito subjetivos e incertos, a exemplo da categoria homoerótica, tudo irá depender do grau de representatividade, de um item em relação a uma categoria e do peso dos atributos do que estará a ser categorizado, e isso depende muito do referencial de cada indivíduo no nível de suas experiências adquiridas.

Uma classe ou categoria é definida pelo que seus membros fazem - como agem ou funcionam - e não apenas por sua composição ou aparência. Nesse 
sentido, parece que os gays masculinos que também - assim como os g0ys entre os anos da década de 1970 a 1990, nunca se identificaram com os valores da cultura gay, mesmo que com uma certa revolta espartana, onde se preza pela aparência não afeminada no convívio social; em que pese o activo, em geral, ser e se sentir mais masculino, a masculinidade por si só, não ganha força conceptual, a ponto de desvincular-se do rótulo gay, pois desde a origem da palavra homossexual - o acto homossexual era essencialmente piguista (não a importar o papel, se activo ou passivo).

E se o conceito de piguista é por definição é 'a expressão comportamental da prática anal masculina', basta que algum homem comporte-se dessa forma para que seja piguista, ou no termo mais contemporâneo, vinculado o actual rótulo gay. Se o comportamento piguista é construído com um forte ou com um fraco desejo intrínseco, com uma excitação que seja mais orgânica ou de forma mais mecânica, acto realizado sem ou com sentimentos mais nobres, realizado com postura ativa ou com postura passiva, etc., não faz diferença, pois a unidade funcional para a categorização é o comportamento e o uso do corpo.

Nesse sentido, falar do comportamento em termo de unidade funcional e essencial para definição de categorias não é, na verdade, uma escolha, mas uma necessidade. Somente com base no comportamento é que torna-se possível ao mesmo tempo não matar a questão do ser difuso, mas ao mesmo tempo diminuir a ambiguidade e com isso reforçar a possibilidade de solidificar-se como categoria ou identidade. Provavelmente o rótulo g0y, que ganhou força nos últimos anos, tenderá a talvez tornar-se apenas um rótulo e nasçam vários outros termos para o mesmo conceito ou categoria homoaffective only, uma vez que o que é e o que não é, e qual seja a sua fronteira conceitual seja aprendida (e apreendida) cada vez mais pelas pessoas.

Como síntese, fica a reflexão registrada, em que pese a aparente novidade do ponto de vista social, por meio desse ensaio não foram encontrados problemas de validade no que diz respeito à categoria g0y, a completude faltante é apenas um critério e parece algo compreensível em virtude do recente resgaste dos seus pressupostos. Nesse sentido, de forma geral e sintética, com base em todos os postulados cognitivos, bem como, também os da área de estudos de categorização de forma mais ampla, não se encontrou erros no sentido da redundância conceitual, de inconsistência interna, de partição ou de circularidade.

Este trabalho não pretende esgotar todos os assuntos relacionados a avaliação de ontologias. Existem muitos enfoques e vários pontos de vista. O que percebe-se na literatura são muitas propostas, porém, pouca coisa está consolidada. E como afirmam vários autores, entre eles Goméz-Pérez (2001) e Murphy (2004) o estudo de ontologias apesar de clássico é ainda um campo que precisa de aprofundamento constante de ideias e diretrizes. Com base nesse levantamento feito sobre o estilo de vida g0y, percebe-se que com o 
reconhecimento do conceito a diversidade se amplia a haver o impacto indubitável de complexificar o propósito da ontologia avaliada. Assim, constatase que a temática g0y ainda está em aberto e são necessários estudos recorrentes para o desenvolvimento desse campo de estudo, sendo o presente uma avaliação original e de caráter exploratória.

\section{DECLARAÇÃO DE CONFLITOS DE INTERESSE}

Não há conflitos de interesse.

\section{REFERÊNCIAS}

Almeida, A., Castro, P., Razuck, F. \& Mamede, W. (2017). Género y identidad masculina en el nuevo milenio: La homo afectividad y la visión social basada en la filosofía de comportamiento GØy (G-cero-y). Psicología, $\begin{array}{llll}\text { Conocimiento } y & \text { Sociedad. }\end{array}$ http://dx.doi.org/10.26864/v7n1.9.

Aranalde, M. (2009). Reflexões sobre os sistemas categoriais de Aristóteles, Kant e Ranganathan. Ciência da Informação, 38(1), 86-108. http://dx.doi.org/10.1590/S0100-19652009000100006.

Barité, M. G. (1998). Las categorías: Aportes para una revisión conceptual y metodológica. Cadernos da F.F.C., 7(1-2), 77-96.

Castro, S. (2008). Ontologia. Rio de Janeiro, RJ: Jorge Zahar.

Castro, P. M. R. (2015, 17 de agosto). O novo rótulo não importa. Importante é o conceito: $O$ mundo está ficando mais complexo e também mais divertido. [Blog]. Recuperado de http://brasilgzeroy.com.br/p/conceitos.html.

Castro, P. M. R. (2016). Gays seus valores versus valores g0ys: Diferentes identidades contemporâneas sob o ponto de vista das prioridades axiológicas. In Anais do $12^{\circ}$ Colóquio Nacional de Representações Gênero e Sexualidades. Campina Grande: Editora Realize. Recuperado em 29 de abril de 2019, de http://www.editorarealize.com.br/revistas/conages/trabalhos/TRABALHO E V053 MD1 SA7 ID1774 02052016172429.pdf.

Cecarello, C. \& Castro, P. M. R (Entrevistados) (2015). Programa Super Pop: Qual a fronteira entre o homoafectivo $(g-y)$ e o homossexual (gay). [Vídeo]. São Paulo, SP/Brasil: RedeTV. Recuperado em 29 de abril de 2019, de https://www. youtube.com/watch? $v=X F-T Z k D U Q c$.

Fiske, S. (2000). Stereotyping, prejudice and discrimination at the seam between the centuries: Evolution, culture, mind, and brain. European Journal of Social Psychology, 30(3), 299-322. https://doi.org/10.1002/(SICI)10990992(200005/06)30:3\%3C299::AID-EJSP2\%3E3.0.CO;2-F 
Foucault, M. (1994). História da Sexualidade II: O uso dos prazeres. Lisboa: Relógio D'água Editores.

Fratman, M. (2015, 30 de abril). Papo sério: O sexo na lei de Moisés. [Blog]. Recuperado em 29 de abril de 2019, de http://brasilgzeroy.blogspot.com.br/2015/04/papo-serio-o-sexo-na-lei-demoises.html.

Furgeri, S. (2006). Representação de informação e conhecimento (Dissertação de Mestrado). Pontifícia Universidade Católica de Campinas, Campinas. Recuperado em 29 de abril de 2019, de http://tede.bibliotecadigital.puccampinas.edu.br:8080/jspui/bitstream/tede/778/1/Sergio\%20Furgeri.pdf.

Gardner, H. (2003). A nova ciência da mente: uma história da revolução cognitiva. São Paulo: EDUSP.

Gómez-Pérez, A. (2001). Evaluation of ontologies. International Journal of Intelligent Systems, 16(3), 391-409. https://doi.org/10.1002/1098111X(200103)16:3\%3C391: :AID-INT1014\%3E3.0.CO;2-2.

Greenwald, A. G. \& Banaji, M. R. (1995). Implicit social cognition: Attitudes, selfesteem, and stereotypes. Psychological Review, 102(1), 4-27. Recuperado em 29 de abril de 2019, de https://faculty.washington.edu/agg/pdf/Greenwald Banaji PsychRev 1995. OCR.pdf.

Heterogoy (2014). Um site para homens modernos e conscientes de seu papel. Recuperado em 29 de abril de 2019, de http://heterogoy.webnode.com/.

Jacob, E. K. \& Shaw, D. (1998). Sociocognitive perspectives on representation. In M. Williams (Ed.), Annual Review of Information Science and Technology (pp. 131-185). Medford: Information Today.

Johnson-Laird, P. N. \& Wason, P. C. (1997). Thinking: Readings in cognitive science. Cambridge: Cambridge University Press.

Kinsey, A. C., Pomeroy, W. B. \& Martin, C. E. (1948). Sexual Behavior in the Human Male, Philadelphia, PA: W.B. Saunders.

Lacerda Neto, A. V. (2007). A homossexualidade em Platão. Recuperado em 29 de abril de 2019, de https://arthurlacerda.wordpress.com/2007/08/12/ahomossexualidade-em-platao/

Lima, G. A. B. (2007). Categorização como um processo cognitivo. Ciências \& Cognição, 11, 156-167. Recuperado em 29 de abril de 2019, de http://www.cienciasecognicao.org/revista/index.php/cec/article/view/663/4 $\underline{44}$.

Macrae, C. N., \& Bodenhausen, G. V. (2000). Social cognition: Thinking categorically about others. Annual Review of Psychology. 51, 93-120. https://doi.org/10.1146/annurev.psych.51.1.93.

Marcuschi, L. A. (2006). A construção do mobiliário do mundo e da mente: Linguagem, cultura e categorização. In N. Miranda \& M. Name (Orgs.), Linguística e cognição (pp. 49-77). Juiz de Fora: Editora UFJF. 
Mareschal, D., Quinn, P. C., \& Lea, S. E. G. (Eds.) (2010). The making of human concepts. Oxford, UK: Oxford University Press.

Markman, E. M. (1989). Categorization and naming in children: problems of induction. Cambridge, MA: MIT Press.

Maddox, W. T. \& Ashby, F. G. (2004). Dissociating explicit and procedural-based systems of perceptual category learning. Behavioural Processes, 66(3), 309-332. https://doi.org/10.1016/j.beproc. 2004.03.011.

Moskowitz, G. (2006). Social Cognition. New York: Guilford Press.

Moreira, A., Alvarenga, L. \& Oliveira, A. P. (2004). O nível do conhecimento e os instrumentos de representação: Tesauros e ontologias. Datagramazero: revista de ciência da informação, 5(6), 1-18. Recuperado em 29 de abril de 2019,

http://www.brapci.inf.br/ repositorio/2010/01/pdf 25cb9ed242 0007645.p df.

Mott, L. (2014, 17 de abril). É um modismo, diz ativista LGBT sobre o movimento dos g0ys [Depoimento concedido à Marina Cohen]. Jornal O Globo. Recuperado em 29 de abril de 2019, de http://oglobo.globo.com/sociedade/e-um-modismo-diz-ativista-lgbt-sobremovimento-dos-g0ys-12223092.

Murphy, G. L. (2004). The Big Book of Concepts. Cambridge: MIT Press.

Norenzayan, A., Smith, E. E., Kim, B. J., \& Nisbett, R. E. (2002). Cultural preferences for formal versus intuitive reasoning. Cognitive Science, 26, 653-684. https://doi.org/10.1207/s15516709cog2605 4.

Nosofsky, R. M. (1988). Similarity, frequency and category representations. Journal of Experimental Psychology: Learning, Memory \& Cognition, 14(1), 54-65. https://psycnet.apa.org/doi/10.1037/0278-7393.14.1.54.

Park, B. \& Judd, C. (2005). Retihinking the link between categorization and prejudice within the social cognition perspective. Personality and Social Psychology Review, 9(2), 108-130. https://doi.org/10.1207/s15327957pspr0902 2.

Pereira, M. (2002). Psicologia Social dos Estereótipos. São Paulo: EPU

Piedade, M. A. R. (1983). Introdução à teoria da classificação. Rio de janeiro: Interciência.

Prieto, M. H. U. (2006). Breves apontamentos sobre o homossexualismo Grego. Lisboa: Impactum Coimbra University Press.

Ptgay (2016, n.d.). Já conhece o movimento g0y? Descubra o que é! [Blog]. Recuperado em 29 de abril de 2019, de http://www.ptgay.net/blog/jaconhece-o-movimento-g0y-descubra-o-que-e/.

Reeder, G. (2000). Same-sex desire, conjugal constructs, and the tomb of Niankhkhnum and Khnumhotep. World Archaeology, 32(2), 193-208. https://doi.org/10.1080/00438240050131180. 
Russel, B. (1945). A History of Western Philosophy. London: George Allen \& Unwin.

Smith, E. \& Medin, D. (1981). Categories and concepts. Cambridge: Harvard University Press.

Soergel, D. (1999). The rise of ontologies or the reinvention of classification. Journal of the american society of information science, 50(12), 1119-1120. https://doi.org/10.1002/(SICI)1097-4571(1999)50:12\%3C1119::AIDASI12\%3E3.0.CO;2-I.

Takacs, J. (2004). The Double Life of Kertbeny. In G. Hekma (ed), Past and Present of Radical Sexual Politics (pp. 26-40). Amsterdam: Mosse Foundation.

Van Dijk, T. A. (2004). Cognição, discurso e interação. São Paulo: Contexto.

Wainer, R. \& Madeira, M. J. P. (1994) A influência da memória de curta duração na categorização difusa a dupla escolha. Psicologia: Reflexão e Crítica, 1(2); 133-144.

Wikipédia, (2016). Desenvolvido pela Wikimedia Foundation. Apresenta conteúdo enciclopédico sobre heteroflexibilidade. Recuperado em 29 de abril de 2019, de: https://pt.wikipedia.org/wiki/Heteroflexibilidade.

Sobre o autor

Nuno de Sá-Teixeira é psicólogo pela Universidade de Coimbra, doutor em Psicologia Experimental pela Universidade de Coimbra - Portugal. Trabalha na linha de interface de pesquisa com a Psicologia Cognitiva, Psicofísica e a Psicologia Matemática, com ênfase em Processos Perceptuais e estudo dos Fatores Humanos. Recebe financiamento de pesquisa em pós-doutoramento da Fundação para a Ciência e Tecnologia. nunoalexandresateixeira@outlook.com

O autor agradece à Fundação para a Ciência e Tecnologia (FCT) pelo financiamento parcial da pesquisa. Agradece, ademais, ao PhD. Johannes Gutenberg e ao grupo de pesquisa sobre Zeitgenössische Sexualitäten da University of Mainz, pelo apoio ao andamento da coleta de informações ao decorrer do pós-doutoramento e ao Dr. Walner Mamede pela leitura da versão inicial do texto.

Recebido em: 27/04/2017

Revisado em: 14/08/2017

Aceito em: $18 / 02 / 2018$ 